\title{
$\mathrm{MDA}$ 기반 학사관리 프로세스 유효성 분석
}

\author{
윤 정 모 $^{+}$김 치 호 $^{+}$
}

요 약

새로운 패러다임의 시스템 개발 접근 방법은 $\mathrm{OMG}$ (Object Management Group)에서 $\mathrm{MDA}$ (Model Driven Architecture)로 표준화하고 있다. $\mathrm{MDA}$ 의 핵심 기술은 모델 중심의 시스템 구현을 위한 기술 구조를 정의하는 것으로 시스템의 설계 및 명세에 대한 구현 기술을 플랫폼 독립 적 모델(PIM : Platform Independent Model)로 설계한 후, 구현 환경에 적합한 플랫폼 종속적 모델(PSM : Platform Specific Model)로 설계하 여 구현환경에 맞는 언어로 변환하는 기술이다. $\mathrm{MDA}$ 의 핵심인 $\mathrm{MOF}$ (Meta-Object Facility), UML, XMI(XML Metadata Interchange), $\mathrm{CWM}($ Common Warehouse Metamodel) 표준 등이 포함된다. $\mathrm{MDA}$ 지원 자동화 툴들은 위의 정보들을 갖고 변환 작업을 수행한 후 실행 가능 한 시스템으로 생산해 내는 것이다.[1]

본 논문에서는 $\mathrm{MDA}$ 기반 접근 방법을 적용하여 학사관리 시스템을 설계 및 구현하고, $\mathrm{MDA}$ 기반 접근 방법에 대한 모델링의 중요성을 강조 하였다. 또한 소프트웨어를 효율적으로 개발하는 방법을 제시하여 플랫폼 독립적 모델(PIM)로 작성하고, 플랫폼 종속적 모델(PSM)을 J2EE 플 랫폼 기반의 $\mathrm{EJB}$ (Enterprise Java Beans)로 변환하는 과정 등을 제시하였다. $\mathrm{MDA}$ 를 지원하는 자동화 툴 및 편집기(Together Architect 2006 for Eclipse, Edit plus 2)와 데이터베이스 모델링 툴(ER/WIN 4.1)을 사용하여 시스템 설계 및 구현을 하였으며, 전통적 개발 프로세스와 $\mathrm{MDA}$ 기반 개발 프로세스에 대한 유효성 분석 결과를 제시하였다.

키워드 : 플랫폼 독립적 모델, 플랫폼 종속적 모델

\section{An Efficiency Analysis of Management System for Academy Affairs Process Based on MDA}

\author{
Kim, Chiho ${ }^{\dagger} \cdot$ Yoon, Jungmo ${ }^{\dagger+}$
}

\begin{abstract}
The system development approach method of the new paradigm, as being standardizing MDA(Model Driven Architecture) in OMG(Object Management Group), the core technique of MDA definite technique structure for system materialization focusing on Model, is to build the design and the statement for system in PIM(Platform Independent Model), Materialization technique, and to build PSM(Platform Specific Model) adapt to materialization environment, and then to be the technique transforming into language Platform suitable to materialization environment.

It includes MOF(Meta-Object Facility), UML, XMI(XML Metadata Interchange), CWM(Common Warehouse Metamodel), the core of MDA. Though these operations MDA support automatic tools product the practicable system after carrying out transform operation with the above information.

In this thesis, it will be approached how to design and materialize the Bachelor management system based on MDA and the importance of modeling should be emphasized by applying to the approach method based on MDA. It should be suggested how to develop software efficiently, written it out in PIM, and suggested the process transforming PSM into EJB by J2EE Platform. The system is designed and implemented using automatic tool, edit machine(Together Architect 2006 for Eclipse, Edit plus2) supporting MDA and Database Modeling tool(ER/WIN 4.1).

In conclusion, it should be suggested the efficiency analysis result for development process of traditional and based on MDA.
\end{abstract}

Key Words : MDA(Model Driven Architecture), EJB(Enterprise Java Beans), PIM(Platform Independent Model), PSM(Platform Specific Model)

\footnotetext{
† 종신회원 : 서울산업대학교 컴퓨터공학과 교수

+ 정 회 원: 서울특별시립 상계직업전문학교 웹프로그래밍과 교사

논문접수 : 2006 년 8월 23 일, 심사완료 : 2007 년 1월 18 일
} 


\section{1. 서 론}

소프트웨어 개발할 때 가장 먼저 고려하게 되는 것은, 바 로 다양하게 많은 종류의 플랫폼 중에서 어떤 플랫폼을 선 택 하는냐가 중요하다. 어떤 플랫폼이 비용이 적게 들고, 개 발 기간이 단축되고, 투자한 것에 비해서 얼마나 많은 유효 성을 가질 수 있는가 등의 고려할 사항이 많다.

이와 같이 통합하고 하나의 표준으로 만들어서 하나의 프 로그래밍 언어, 하나의 미들웨어, 하나의 네트워크 프로토콜, 하나의 운영체제는 결국 각각 개발한 벤더들이 합의하여 서 로 연동을 가능하게 하는 것이다.

$\mathrm{MDA}$ 접근방법은 산재한 플랫폼 독립적 모델인 $\mathrm{PIM}$ 을 $\mathrm{UML}$ 로 작성한 후, 이를 구현 환경과 관련한 플랫폼 종속적 모델인 $\mathrm{PSM}$ 을 만들고, 플렛폼 종속적 모델을 통해 소스코 드, 설정파일 및 기타 산출물을 자동으로 생산해 냄으로써 시스템을 보다 효율적으로 유지 및 통합 할 수 있다.

$\mathrm{MDA}$ 가 성공적으로 이루어지기 위해서는 $\mathrm{MDA}$ 지원 도 구에서 플렛폼 독립적 모델에 플랫폼 종속적인 정보를 제외 한 모든 정보를 모델링 할 수 있어야 하고, 플렛폼 독립적 모델의 완전성을 검증 할 수 있어야 한다. 또한 자동화된 매핑 기준을 제공하여 플렛폼 독립적 모델을 각종 플랫폼에 종속적인 $\mathrm{PSM}$ 으로 변환할 수 있어야 하고 설계 정보로부 터 자동적으로 소스코드를 생성할 수 있어야 한다.

플렛폼 독립적 모델의 효과적인 재사용을 위해서는 도메 인 아키텍처 재사용의 기능도 지원해야 한다. 따라서, $\mathrm{MDA}$ 기반 접근 방법으로 학사관리 시스템을 개발 사례로 해서 전통적 개발 프로세스와 $\mathrm{MDA}$ 기반 개발 프로세스에 대한 유효성 분석을 제시하였다.

\section{2. 관련 연구}

\subsection{MDA(Model Driven Architecture)}

2001년 9월 $\mathrm{OMG}$ 는 네트워크 기반 환경의 소프트웨어 개 발 시 다양한 종류의 구현 언어, 미들웨어, 네트워크 프로토 콜 등 어떠한 것을 선택하여 개발하느냐는 문제점을 해결하 고자 그 해 9월에 아키텍처의 표준 모델인 $\mathrm{MDA}$ 를 제안하 였으며, $\mathrm{MDA}$ 의 핵심은 플랫폼에 독립적인 모델을 구현 환 경에 적합한 플랫폼 종속적 모델로 자동 변환 가능한 구조 를 정의한 것이다.[1,2,3,4]

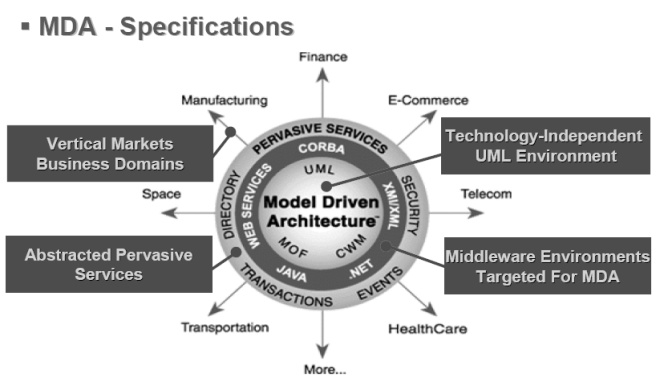

(그림 2.1) $\mathrm{MDA}$ 의 기본 구조
- MDA - Models

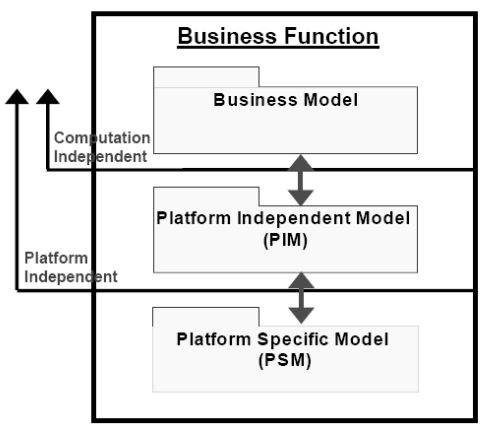

(그림 2.2) $\mathrm{MDA}$ 의 모델

(그림 2.1)은 $\mathrm{MDA}$ 의 기본 구조를 나타낸 것이며, (그림 2.2)는 $\mathrm{MDA}$ 의 모델을 나타낸 것이다.

플랫폼에 독립적인 모델을 설계하고, 이를 자동화 도구를 이용하여 플랫폼에 맞는 종속적인 모델 및 시스템으로 개발 함으로써 생산성 향상이 구현 단계에서 가능하게 하고, 메 타모델에 기반을 둔 시스템들의 일반적인 호환성을 기대할 수 있게 해주는 장점을 가지게 된다.

$\mathrm{MDA}$ 는 $\mathrm{CORBA}$ 와 같이 설계 수준의 표준이다.[5]

$\mathrm{MDA}$ 는 오래 전부터 소프트웨어 공학도들에 의해 만들어 지고 정제되어 왔으며, 대부분의 소프트웨어 통합(SI) 프로 젝트에서 적용되고 있는 '비즈니스 모델링 $\rightarrow$ 요구사향 분 석 $\rightarrow$ 설계 $\rightarrow$ 구현' 방식의 톱 다운(Top Down) 모델의 개 념을 갖는다.

(그림 2.3)과 같이 대표적인 객체지향 방법론인 UP (Unified Process)에서는 비즈니스 모델링을 통해 전체 비즈 니스를 파악하고, 유스케이스 다이어그램을 통해 요구사항 을 모델링하며 이것으로 분석 모델을 만든다. 이때의 분석 모델을 기반으로 적절한 플랫폼과 설계 메커니즘을 적용해 서 플랫폼 종속적인 설계 모델을 만들고 이를 기반으로 구 현한다.

요구사항 모델은 시스템을 개발자 관점으로 가져오기 전 에 고객과 의사소통하기 위한 수단이고, 분석 모델에서는 어떤 환경에서 어떤 제약 조건을 갖고 구현될지는 생각

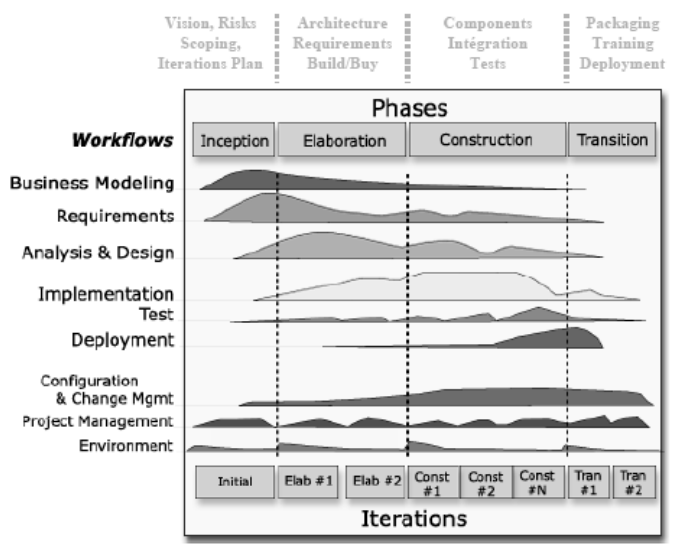

(그림 2.3) Unified Process 단계 
하지 않고 순전히 비즈니스만을 반영한 모델을 모델링 한 다. 그리고 설계 모델에서는 비기능적 요구사항을 반영해서 세부 설계를 하고 이 모델을 이용하여 구현 소스 코드를 만 든다.

$\mathrm{MDA}$ 는 $\mathrm{UML}$ 을 통해서 시스템을 모델의 형태로 설계 및 명세 하는 것과 시스템의 개발 라이프 사이클 전체에서 모 델 역할에 대한 것이다. $\mathrm{MDA}$ 개발 방법은 우선 플렛폼 독 립적 모델을 정의함으로 시작한다.

플렛폼 독립적 모델은 특정한 기술 플랫폼이나 기반 기술 에 독립적인 방법으로 시스템을 설계한 모델을 말한다. 플 렛폼 독립적 모델은 단일 플랫폼에 매여 있지 않고 프로그 래밍 언어에 독립적이기 때문에 다른 시스템으로의 가교 역 할을 할 수 있다. $\mathrm{MDA}$ 에서는 이러한 플렛폼 독립적 모델 에 정형화된 변환 법칙을 사용해서 플렛폼 종속적 모델을 생성한다.

플렛폼 종속적 모델은 특정 기술에 종속적인 요구사항 들이 포함된 시스템 모델 정보이다. 여기서 플렛폼 독립적 모델 과 플렛폼 종속적 모델 모두 UML로 기술된다. 마지막으로 플렛폼 종속적 모델을 통해서 실제로 동작하는 구현 코드를 만들어 낸다.

$\mathrm{MDA}$ 방식으로 개발된 시스템은 다음과 같은 이점을 지 니게 된다.[5]

(1) 기술 변화 상황에 효율적으로 대처할 수 있다. $\mathrm{MDA}$ 방식으로 개발된 시스템은 플렛폼 독립적 모델을 통 해서 변경된 기술 플랫폼으로 이식이 쉽게 이루어질 수 있기 때문이다.

(2) 시스템 인프라 변화에 유연하게 대처할 수 있다.

(3) $\mathrm{MDA}$ 방식으로 개발된 시스템은 그 시스템의 유지보 수 비용이 적으며 시스템의 수명이 길다. 따라서 투 자 비용이 보존된다

\subsection{4계층 메타 모델링 구조}

2000년도에 접어들면서 UML을 보다 체계적으로 변화시 키지 않고서는 새로운 개발 환경, 새로운 개발 접근 방법, 새로운 도구와의 호환성 등을 $\mathrm{UML}$ 에 적용할 수 없다는 것 이 명백해졌다. 그 결과 보다 근본적인 개선 작업이 $\mathrm{UML}$ 에 이루어졌으며 2003년도에 UML2.0이 발표되었다.[3]

(그림 2.4)는 $\mathrm{MOF}$ (Meta-Object Facility)와 UML 모델들 간의 관계를 나타낸다. 이러한 4계층 메타모델링 구조는 $\mathrm{MDA}$ 기반 시스템 모델링의 기본 구조이다. $\mathrm{MDA}$ 에서 $\mathrm{UML}$ 2.0 은 구현 기술에 플렛폼 독립적인 모델이나 구현 환경에 적합한 플렛폼 종속적인 모델 작성시에 사용되기도 하며, $\mathrm{MOF}$ 나 $\mathrm{CWM}$ (Common Warehouse Metamodel)을 표현하 기 위한 기호로서의 기반을 제공하기도 한다.

$\mathrm{MDA}$ 기반 시스템 개발의 첫 번째 단계가 $\mathrm{UML} 2.0$ 을 이용하여 구현하고 독립적 모델을 작성하는 것이다.[8,9,10]

$\mathrm{UML} 2.0$ 을 모델링 영역의 경계를 확립하는 프로파일 (profile)은 누구나 정의할 수 있으나, CORBA나 EDOC

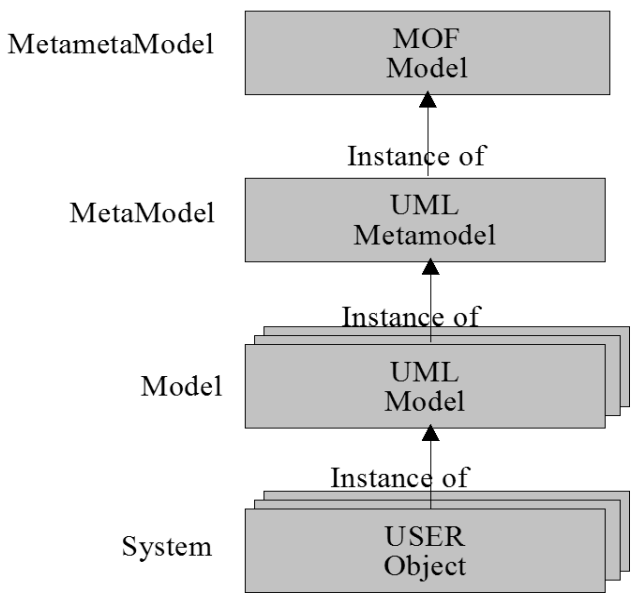

(그림 2.4) 4계층 메타 모델링 구조

(Enterprise Distributed Object Computing) 등 OMG의 표 준 프로파일과 같이 다수의 사람들이나 기업에 의해 정의된 프로파일이 가장 유용하게 사용된다. 이렇게 표준화된 프로 파일은 구현 독립 모델로부터 구현 종속 모델을 생성하거나, 구현 종속 모델로부터 코드를 생성하기 위한 규칙들을 제공 하게 된다.

\section{MDA를 적용한 학사관리 시스템 설계 및 구현}

\section{1 시스템 개요}

$\mathrm{MDA}$ 를 적용하여 학사관리 시스템을 구현하는 과정에 대 하여 설명하고, 이 시스템 개발 과정을 통하여 요구사항을 분석하고, 플렛폼 독립적 모델을 구축하여 플렛폼 종속적 모델 과정에서 $\mathrm{J} 2 \mathrm{EE}$ 기반으로 $\mathrm{EJB}$ 를 구현하게 된다. $\mathrm{MDA}$ 기술을 지원하는 자동화 도구(Together Architect 2006)와 데이터베이스 모델링 도구(ER/WIN 4.1)를 이용하여 소스코 드를 생성한 애플리케이션을 구현한다.

3.2 도메인 모델(CIM : Computation Independent Model) 설계

$\mathrm{CIM}$ 은 시스템 요구사항과 환경에 대한 것을 기술하는 모 델로써 도메인 모델, 비즈니스 모델이라고 할 수 있다. 본 논문에서는 $\mathrm{MDA}$ 를 적용한 학사관리 시스템을 설계 구현한 다. 이 시스템은 3 Tier 구조를 갖고 있으며 교직원 누구나 쉽게 접속해서 학사 업무를 할 수 있도록 하고, 클라이언트 는 웹 기반의 JSP 클라이언트가 필요하다.

재학생 및 졸업생, 예약 접수자는 홈페이지를 통해서 증 명서 발급 및 예약 접수를 할 수 있도록 하고, 학사업무를 관리하기 위한 독립적인 데이터베이스를 사용하며, 미들웨 어는 학사업무를 수행하기 위한 비즈니스 로직을 구현한다.

전체적인 시스템 개요는 (그림 3.1)과 같으며, 시스템 사 용자는 학사관리 시스템으로부터 보안인증, 기초자료, 재료 수불, 예약접수, 입학지원, 학적 관리, 교육계획, 교육실적, 통계자료, 전자결제, 증명서발급 및 홈페이지와 연동하여 처 리할 수 있도록 지원한다. 


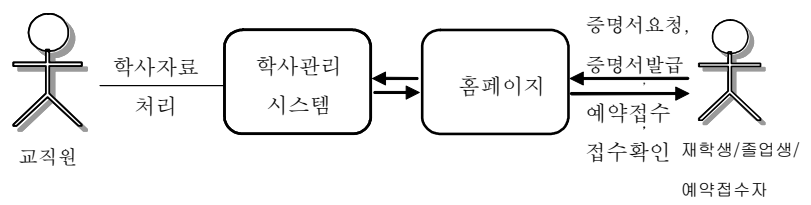

(그림 3.1 ) 학사관리 시스템 구조

\section{2 .1 학사관리 시스템 도메인 모델 작성}

학사관리 시스템의 각 도메인에 대한 상세 부분의 정의는 다음과 같다.

(1) 사용자(교.직원)들의 원활한 학사업무를 위한 실시간 업무처리 및 데이터베이스 관리를 위한 학사관리 시 스템 서버

(2) 재학생 및 졸업생들에 대한 증명서 발급을 위한 홈페 이지 서버

(3) 예약 접수자 들에 대해 학사관리 시스템에 직접 접근 이 불가능함으로 인해 웹 서버(홈페이지)를 통한 예 약접수

(그림 3.2)는 학사관리 시스템의 도메인 모델을 설계 하였다.

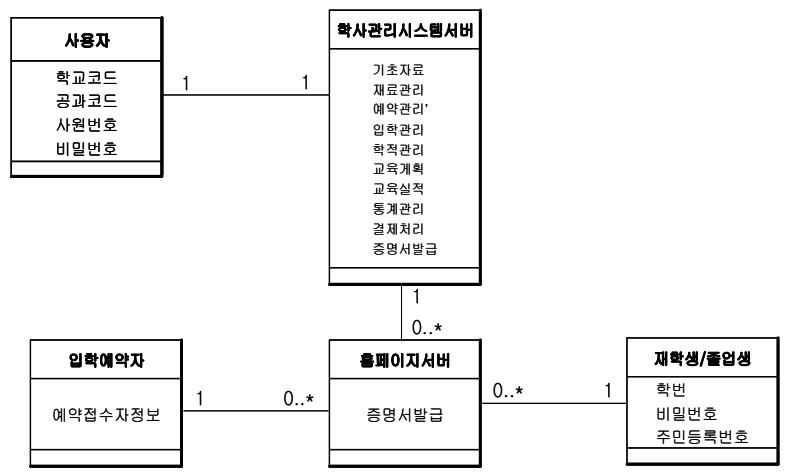

(그림 3.2) 학사관리 시스템 도메인 모델

\section{2 .2 학사관리 시스템 유스케이스 다이어그램}

학사관리 시스템을 설계하기 전에 사용자로부터 요구사항 을 명확하게 정의하고 분석하여 향후 개발을 진행하기 위해 유스케이스 다이어그램을 통해서 도식화 한다. (그림 3.3)은 학사관리 시스템에 대해 전체적인 유스케이스 다이어그램을 표현하였다.

학사관리 시스템의 전체 패키지 구성을 살펴보면 크게 사 용자 인터페이스와 비즈니스 부분으로 나누어 관리한다. 첫 번째 사용자인터페이스에는 사용자에게 사용자 인터페이스 제공 및 자료 입력 받는 패키지들로 구성되어 있고, 두 번 째 비즈니스에는 여러 개의 패키지에서 공통으로 사용되고 있는 재사용 가능한 비즈니스 로직으로 구성되어 있으며, 데이터베이스 접근은 사용자 인터페이스에 입력된 정보를 비즈니스 로직에서

받아 스토어드프로시저의 파라미터에 값을 넘겨주고, 스 토어드프로시저를 실행해 줌으로서 처리한다.

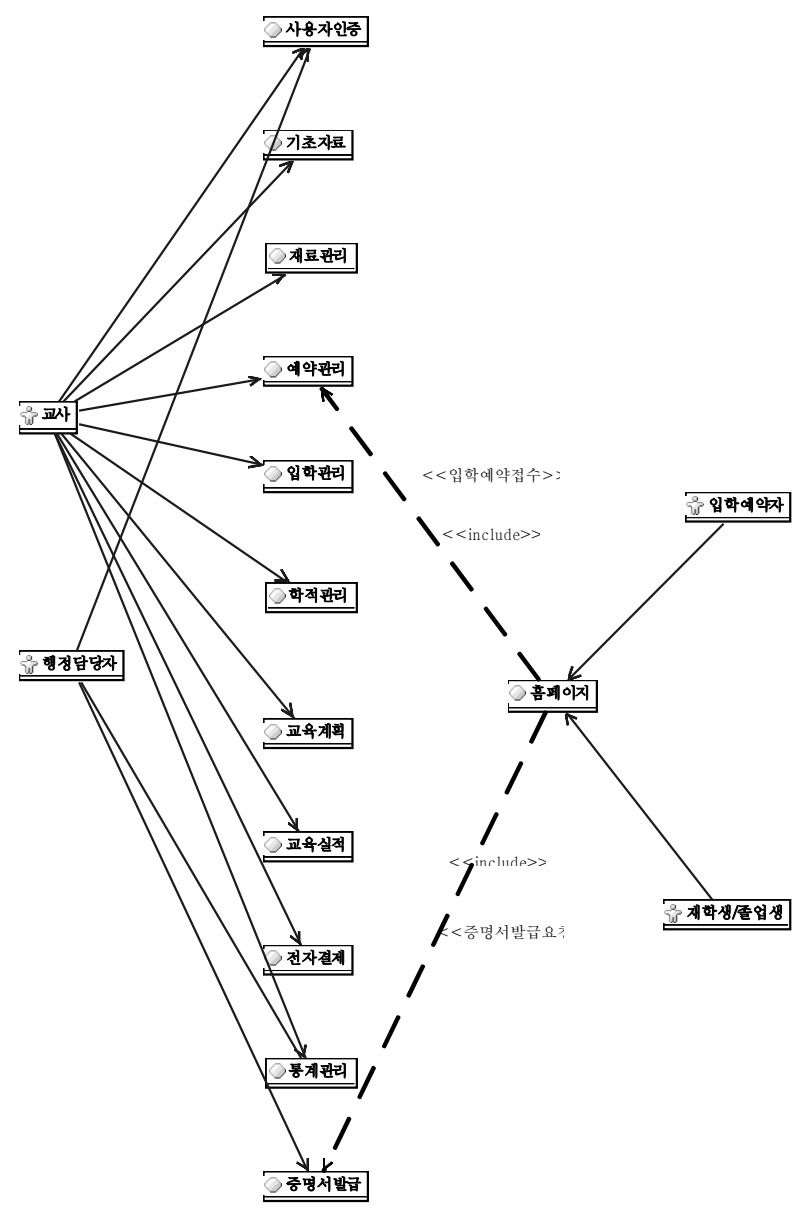

(그림 3.3) 학사관리 시스템 유스케이스 다이어그램

사용자 인터페이스 레이어는 학사관리 시스템이 사용자에 게 제공하는 주요 기능들이 포함되었고, 이 시스템의 사용 자는 교.직원(교사, 행정담당자)만 자신의 계정으로 로그인 하여 접근이 가능하고, 재학생, 졸업생, 입학예약자들은 홈페 이지를 통해서 데이터베이스에만 접근이 가능하도록 되어 있고, 비즈니스 로직 레이어는 각각의 패키지에서 공통으로 사용되고 있는 재사용이 가능한 비즈니스 로직과 데이터베 이스에 정보를 제공하는 컨트롤러 기능으로 시스템에서 필 요한 정보를 저장하는 기능들로 구성 하였다. (그림 3.4)는 사용자 인터페이스 레이어에 포함된 패키지들의 관계를 표 현 하였다.

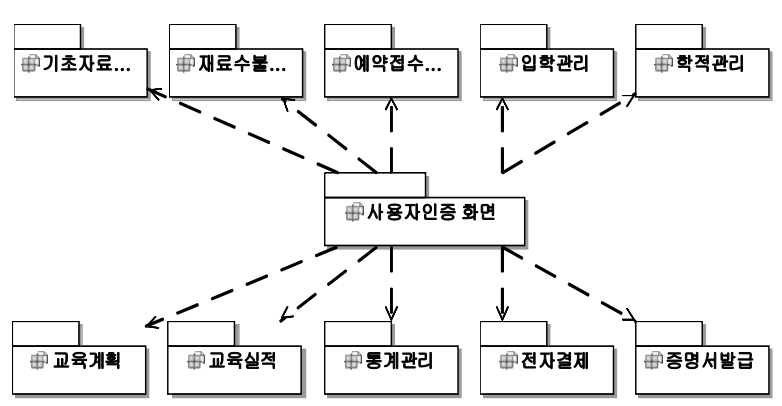

(그림 3.4) 사용자 인터페이스 레이어 패키지의 구성 


\section{3 플랫폼 독립적 모델 설계}

$\mathrm{MDA}$ 를 적용한 개발 프로젝트의 시작은 플랫폼 독립적 모델을 구축 하면서 부터이다. 요구사항을 분석하고 구현 플랫폼 환경은 고려되지 않은 모델링으로써 순수한 플랫폼 독립적 모델이며, $\mathrm{UML}$ 모델링 도구인 Together Architecture 2006을 사용하여 시스템을 모델링한다.

\subsection{1 플랫폼 독립적 모델 학사관리 시스템 설계}

클래스 다이어그램 표현은 MVC(Model View Control) 기반으로 클래스의 역할을 보다 쉽게 구분하고자 표현하였 다. 클래스 위에 확장 메커니즘인 스테레오 타입 등을 사용 하여 표현을 상세하게 설계 하였다. (그림 3.5)는 클래스 다 이어그램으로 학사관리 시스템 중 사용자 로그인과 입학관 리 클래스만 나타내었다.

〈표 3.1〉각 클래스 설명

\begin{tabular}{|c|l|}
\hline 클래스명 & \multicolumn{1}{|c|}{ 클래스 내용 } \\
\hline \hline SchoolVO & 학교정보 관리(Value Object) \\
\hline ClassVO & 공과정보 관리(Value Object) \\
\hline LoginProcessor & 사용자 로그인 처리 \\
\hline UserVO & 사용자(교.직원)정보 관리(Value Object) \\
\hline LoginManager & $\begin{array}{l}\text { 사용자 로그인 관리 로직 } \\
\text { (스토어드프로시저를 호출하는 로직 클래스) }\end{array}$ \\
\hline ApplicantVO & 입학지원자 정보 관리(Value Object) \\
\hline ApplicantProcessor & 지원자 정보 처리 \\
\hline
\end{tabular}

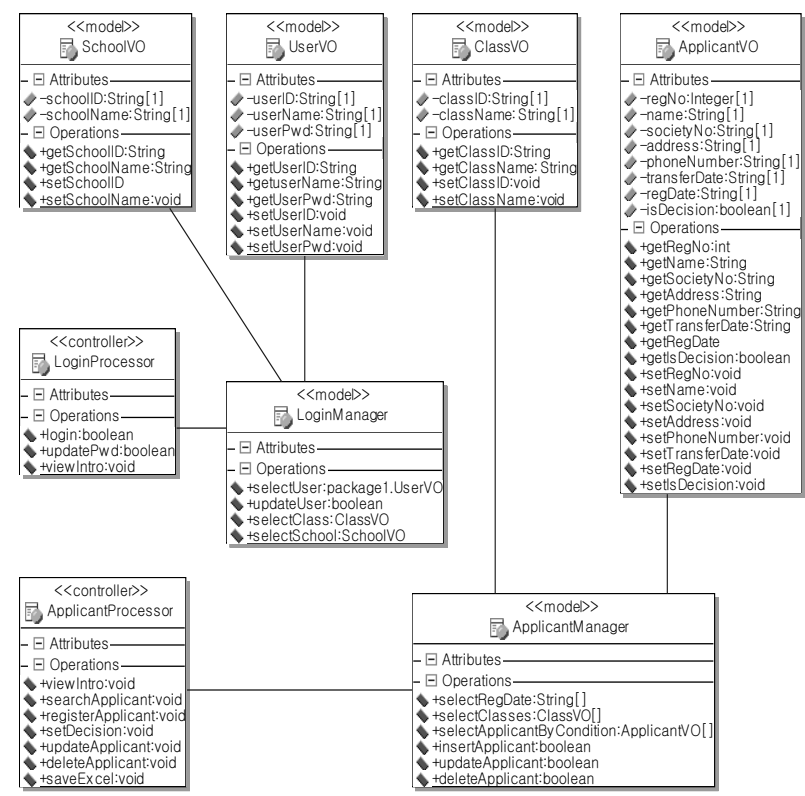

(그림 3.5) 학사관리 시스템[사용자 로그인 및 입학관리]의 클래 스 다이어그램

3.3.2 플랫폼 독립적 모델 - 사용자인증 패키지 설계 (그림 3.6)은 사용자인증 패키지로서, LoginProcessor는 사용 자에게 사용자 인터페이스에서 요구되는 정보를 바탕으로 사용자 로그인 관리 로직을 호출해서 결과를 제공하고, LoginManager는 로그인한 사용자 체크 및 스토어드프로시

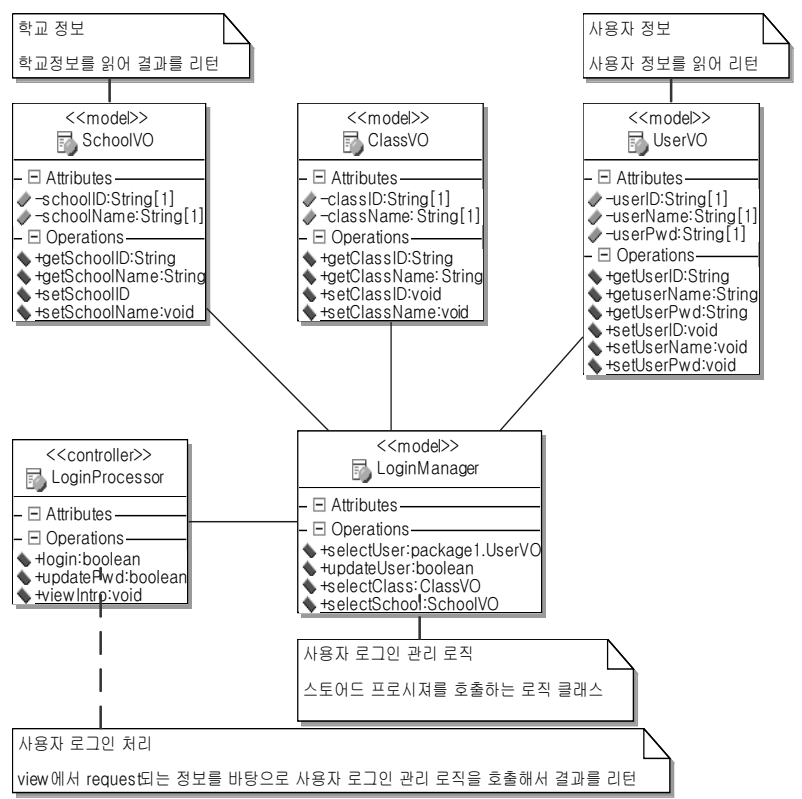

(그림 3.6) 사용자 인증 패키지

저를 호출하고 프로시저에서 작업한 결과를 받아 SchoolVO, ClassVO, UserVO에 대하여 Value Object를 생성한다.

\section{4 플랫폼 종속적 모델 구현}

플랫폼 독립적 모델로 설계한 학사관리 시스템을 플랫폼 종속적 모델로 매핑 룰을 통하여 3 Tier로 구성하여 변환한 다. 각 Tier는 서로 다른 플랫폼을 갖게 된다. (그림 3.7)은 $\mathrm{MDA}$ 의 모델 변환 개념도를 나타내었으며, (그림 3.8)은 플 렛폼 독립적 모델을 가지고 플렛폼 종속적 모델로 자동 변

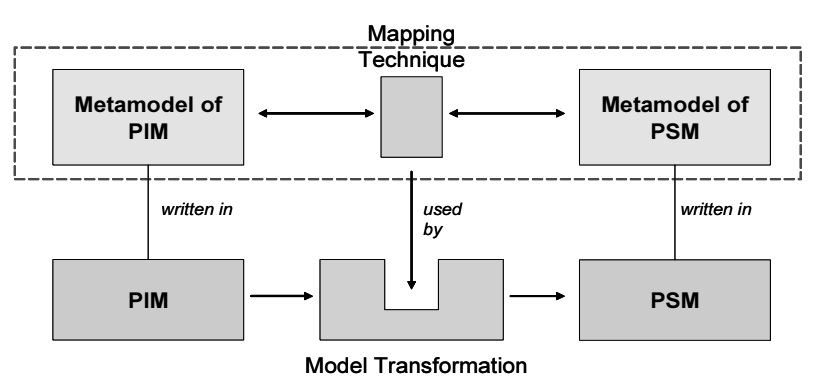

(그림 3.7) $\mathrm{MDA}$ 의 모델 변환

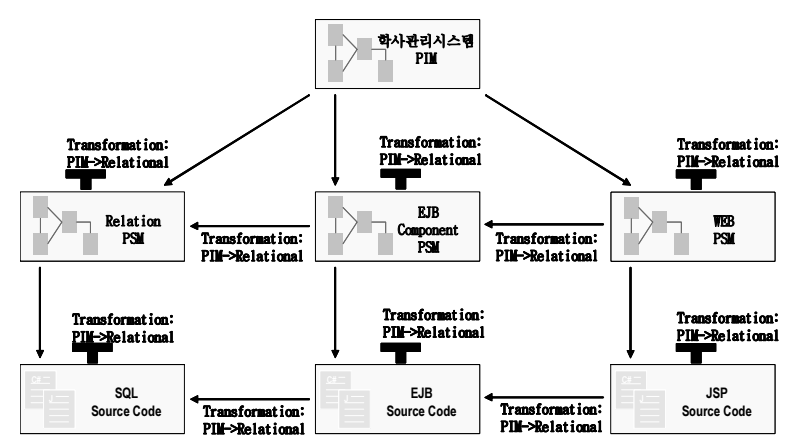

(그림 3.8) 학사관리 시스템 변환 모델 
환을 통해서 3 Tier 구조로 나타내고 있다. 학사관리 시스템 에서는 Entity Bean을 사용하지 않고 데이터베이스의 스토 어드프로시저를 사용하므로 데이터베이스와 관련한 모델은 변환하지 않는다.[8,11]

\subsection{1 플랫폼 종속적 모델 EJB SessionBean 구현}

사용자 인증 패키지 다이어그램을 가지고, 플렛폼 독립적 모 델에서 플렛폼 종속적 모델로 변환하여 구현 하려고 한다. 플렛 폼 독립적 모델에서 설계한 클래스는 플렛폼 종속적 모델로 매 핑 되면서 그 속성에 따라 SessionBean과 EntityBean으로 나뉜 다. 여기서 EntityBean은 변환하지 않는다. SessionBean으로 매 핑되는 모델은 $\mathrm{MDA}$ 도구에 의해 Local Interface와 LocalHome Interface를 추출한다. LocalInterface의 LocalMethod는 플렛폼 독립적 모델에서 특정 메소드에 로컬 메소드 성격을 기술해 만 들어진다. 그리고 실제 비즈니스를 갖는 $\mathrm{EJB}$ 구현 클래스가 생 성된다. 이 구현 클래스에서는 플렛폼 독립적 모델에서 정의한 비즈니스 메소드도 만들어진다.

$\mathrm{EJB}$ 플랫폼에 대한 플렛폼 종속적 모델은 $\mathrm{UML}$ 프로파일 (UML Profile for EJB)에 정의된 표준 $\mathrm{EJB}$ 표현 형식으로 기술 되고, 이후 소스코드로 변화되기 위한 중간 단계인 플렛폼 종속 적 모델을 완성하게 된다. 또한 추가적으로 추가해야 하는 소스 코드는 편집기를 활용하여 소스코드를 추가하면 된다.

본 논문은 플렛폼 독립적 모델에서 미들웨어를 $\mathrm{EJB}$ 로 선 정해서 자동화 툴인 Together Architecture 2006을 이용하 여 플렛폼 종속적 모델을 추출했다. 사용자 인증 및 입학관 리 패키지의 각각 한 개의 클래스 LoginProcessor 클래스와 ApplicantProcessor 클래스를 플렛폼 종속적 모델로 매핑 하 면서 SessionBean으로 변환된 것을 볼 수 있다. (그림 3.9) 는 플렛폼 독립적 모델을 플렛폼 종속적 모델로 매핑된 두 개의 SessionBean 클래스를 확인한다. 그리고 추가적으로 세부적인 코드를 추가로 작성해야 할 경우 해당 그림을 더 블 클릭하면 (그림 3.10)과 같이 자동 생성된 소스 코드가 화면 하단에 나타나고, 여기에서 세부적인 코드를 추가 및 수정할 수 있다. 또한 다른 방안으로는 소스 코드 자동 생 성 후 편집기를 통하여 추가적으로 세부적인 코드를 추가 및 수정할 수 있다.

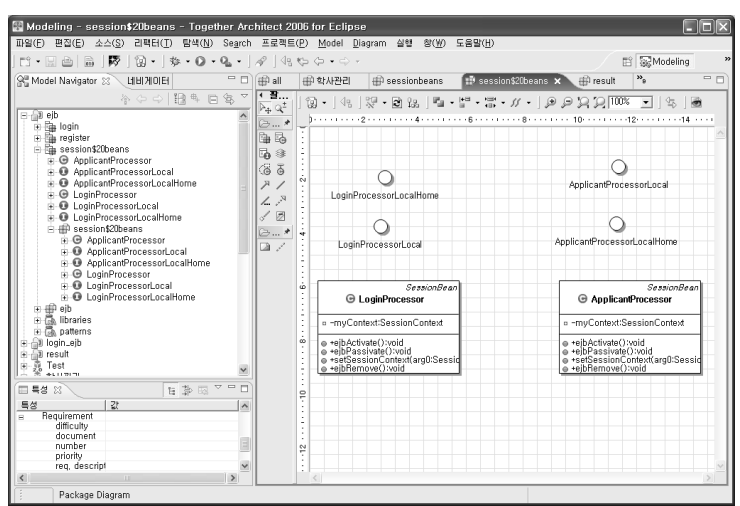

(그림 3.9) PIM의 사용자인증, 입학관리 패키지를 PSM SessionBean 으로 변환

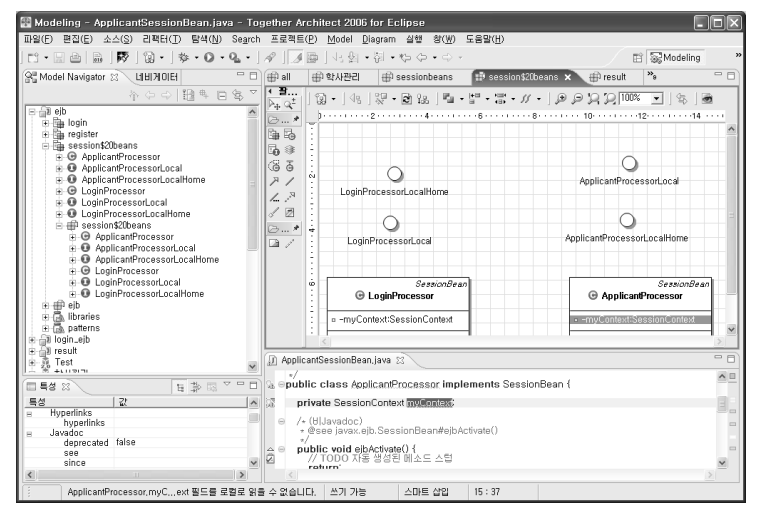

(그림 3.10) PSM SessionBean으로 변환 후 상세코드 추가작성 및 수정

3.5 학사관리 시스템 결과 화면

$\mathrm{J} 2 \mathrm{EE}$ 플랫폼의 $\mathrm{EJB}$ 로 구현한 학사관리 시스템 결과 화 면을 간단하게 보여준다.

(그림 3.11)은 학사관리 시스템에 대한 사용자 인증처리 화면이다. 교직원(교사와 행정직원)일 경우 로그인이 가능하 고, 그 외에는 접근을 불허한다. 학교, 학과, 직원번호와 비 밀번호를 입력하고 로그인 버튼을 클릭함으로 인증처리를 한다.

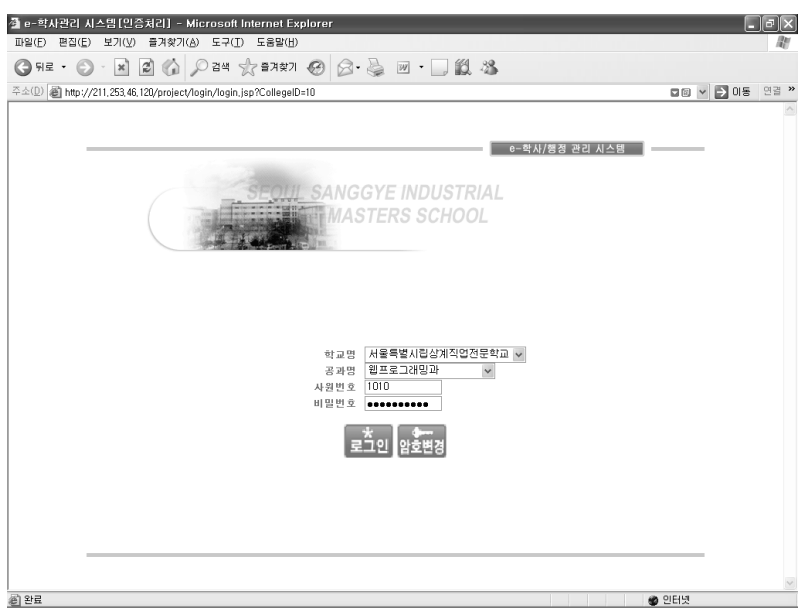

(그림 3.11) 학사관리 시스템 로그인 화면

\section{4. 개발 프로세스에 대한 유효성 분석}

\subsection{MDA 접근방법}

$\mathrm{OMG}$ 에서 $\mathrm{MDA}$ 를 정의한 내용은 "대규모 시스템을 아키 텍처 기반으로 개발하는데, 모델링 기법을 사용하고 각각의 모델의 변환을 통해 시스템을 구축하며 이러한 모든 활동은 자동화된 도구의 도움을 받는다는 것이다.” 라고 정의되어 있다.[3]

첫 번째, 모델링을 이용한 소프트웨어 개발은 고객의 요 구사항을 초기 모델을 만들고, 이로부터 각종 정보를 첨가 하면서 모델을 변경시켜 최종적으로 우리가 필요한 소스코 
드를 생성함으로써 실제적으로 실행 가능한 시스템을 구축 하는 것이다. 즉 개발의 모든 활동은 모델을 만들고 이 모 델에 각종 정보를 첨가하고 보충하여 더욱 세밀한 모델로 변환시켜서 작동 가능한 소스코드를 생성하는 것이다.

두 번째, 각 변환에서 사용되는 도메인 정보나 각종 경험 적인 지식 및 플랫폼에 관한 정보들이 축적되는 과정에서 이러한 지식들이 정형화됨으로써 표준화된 지식 패턴이나 아키텍처의 유도를 촉진하게 된다. 초기에 $\mathrm{GoF}$ 패턴 밖에 없었던 패턴들이 현재는 많은 수의 패턴들이 발표되고 있으 며, 재사용의 중요성이 소프트웨어 개발 생산성에 부각 되 었다.

세 번째, 잘 통합된 개발 도구의 도움을 받을 수 있게 된 다. 완전히 통합된 도구에 대한 논의를 학술적으로 시작한 것은 십 년 이상 진행되어 왔지만, 실제적인 개발에 적용하 지 못한 이유는 통합에 대한 가치를 사용자들이 충분히 수 용하지 못했기 때문이다. 그러나 $\mathrm{MDA}$ 가 지원되면 요구사 항으로부터 테스트까지 통합 개발 환경에 대한 요구가 강하 게 요청될 것이며, 이러한 요건을 만족 시키는 도구들이 $\mathrm{MDA}$ 도구의 주요 부분을 차지하게 될 것이다.

마지막으로, 충분히 자동화된 도구가 지원된다면, 비즈니 스 모델링만으로도 실제적으로 작동하는 시스템을 구축할 수 있다는 것이다. 즉 IT 전문가가 아닌 도메인 전문가가 비즈니스에 대한 정책을 모델링 하면 바로 작동하는 제품을 구축할 수 있게 된다. 빠른 시간 안에 비즈니스의 요구사항 을 정확히 운용 환경으로 적용시키는 체제가 완성되는 것이 다. 금융 상품을 빨리 시장에 출시하기 위해서는 이를 지원 하는 IT 서비스도 역시 빨리 지원돼야 가능하기 때문이다 [8,12].

\subsection{MDA 적용 방식과 전통적 개발 방식 비교분석}

$\mathrm{MDA}$ 개발 방식과 기존의 개발 방식은 차이가 있다. 전 통적인 방법은 최종적으로 개발자가 효과적으로 하나의 거 대한 시스템을 직접 손으로 구현해야 한다는 것에 초점이 맞춰져 설계되어 있다. $\mathrm{MDA}$ 개발 프로세스 모델은 요구사 항을 정확히 분석하고, 비즈니스를 세밀하게 모델링 하여 플렛폼 독립적 모델을 구축하도록 하고 있다. 이 플렛폼 독 립적 모델은 플렛폼 종속적 모델로 변환하기 위한 표준 지 침인 QVT(Quality View Transformation)를 기술하고, 이 정보들을 중심으로 플렛폼 종속적 모델을 추출하고 소스코 드를 추출하면서 플랫폼 아키텍처 모델, 테스트 코드, 구현 소스코드 등이 작성 된다. (그림 4.1)은 전통적 개발 방식(a) 과 $\mathrm{MDA}$ 적용 방식(b)을 확인할 수 있다.

기존에는 대략 전체적인 개념만을 작성하고 필요에 따라 세부 설계를 하여 개발하였으며, 한번 작성한 모델이 구현 단계에서 변화하는 경우가 빈번했다. 그러나 $\mathrm{MDA}$ 개발 프 로세스에서는 플렛폼 독립적 모델 구축 시 모든 비즈니스에 대한 정적 구조 및 동적인 구조를 완벽하게 기술해야 완전 한 애플리케이션을 구축할 수 있다. 결국 $\mathrm{MDA}$ 개발 프로 세스로 인해 구축돼야 할 핵심이 변화되고, 이에 따라 개발

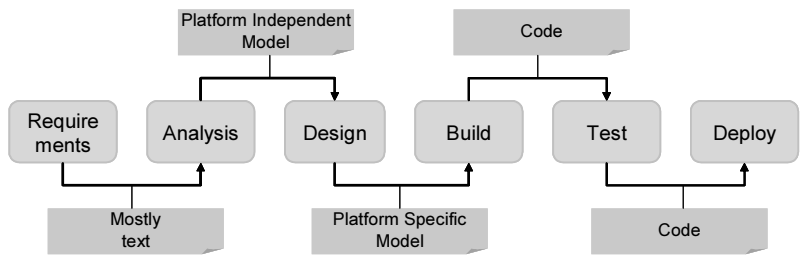

(a) 전통적 개발 방식
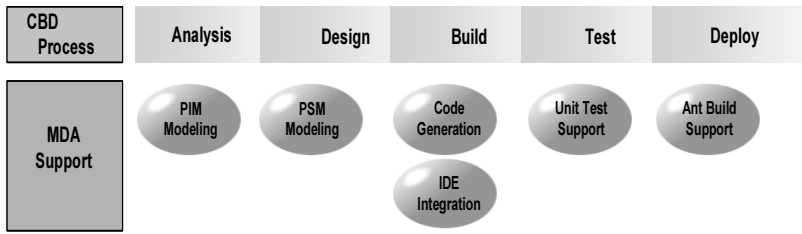

(b) $\mathrm{MDA}$ 적용 방식

(그림 4.1) 전통적 개발 방식(a)과 MDA 적용 방식(b)
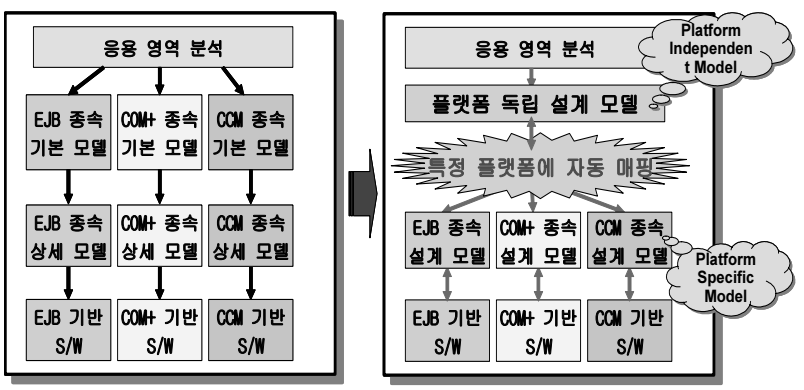

구현 종속적 개별 플랫퐁 지향 개발 모델 주도의 멀티 플랫폼 지향 개발

(그림 4.2) 단일 플랫폼 지향 개발 절차와 다중 플랫폼 지향 개 발 방식
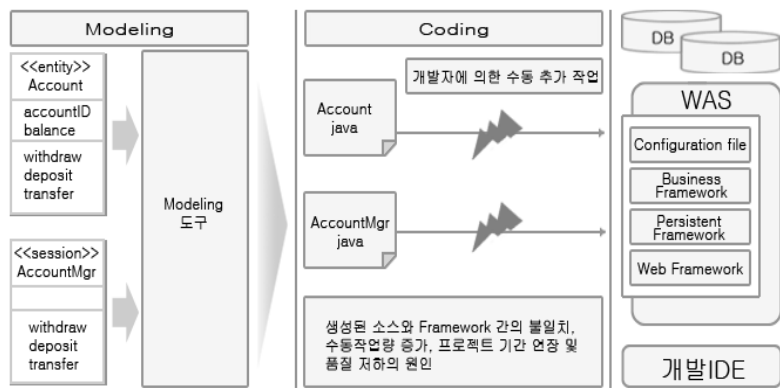

(그림 4.3) 기존 개발 방식

자의 역할도 각 핵심을 실현하는 형태로 변화해야 한다. (그 림 4.2)는 단일 플랫폼 지향 개발 방식과 다중 플랫폼 지향 개발 방식의 흐름을 보여 준다.[6]

$\mathrm{MDA}$ 는 기존 개발 프로세스와 확실히 다른 소프트웨어 개발 패러다임을 갖고 있다. 기존 방법은 분석, 설계 작업을 통해 나온 모델을 개발자가 직접 구현하는데 반해, $\mathrm{MDA}$ 는 개발 작업의 중심이 플랫폼 독립적인 모델(PIM)을 구축하는 것에 맞춰져 있고, 이후에는 $\mathrm{MDA}$ 지원 툴을 사용해 변환 작업을 하여 최종 소스코드, 애플리케이션을 만들어 내는 것이다. $\mathrm{MDA}$ 중심에는 플렛폼 독립적 모델이 있고, 툴과 


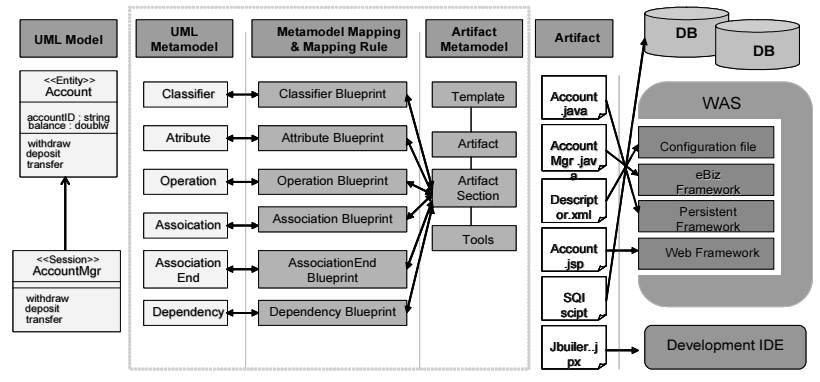

(그림 4.4) MDA 적용 방식

변환 작업이 애플리케이션을 만들어내는 데 중요한 역할을 한다. (그림 4.3)은 기존 개발 방식의 패러다임이다.[6,10]

$\mathrm{MDA}$ 개발 방식에서는 기술한 비즈니스 규칙이 그대로 마지막 소스코드로 구현되기 때문에 상당히 주의해야 한다. 플렛폼 독립적 모델은 시간이 아무리 지나도 비즈니스 규칙 이 바뀌지 않는 이상 변경되지 않는다. 이후에 시스템이 새 로운 비즈니스 기회를 맞아 다른 외부의 시스템과 연동을 위한 아키텍처로 변경되더라도 이것은 플랫폼 선택에 대한 문제이다. 그리고 새롭게 변화되는 플랫폼과의 연동 문제는 플렛폼 종속적 모델에서 브리지를 통해 해결할 수 있다. 개 발자는 비즈니스 규칙을 Java, $\mathrm{C}^{++}, \mathrm{C \#}$ 같은 프로그래밍 언 어로 소스코드를 작성하는 것이 아니라 설계 모델과 비즈니 스 규칙을 기술하기 위한 새로운 도구를 이용해 프로그래밍 된다.

기존의 개발 프로세스에서 이전의 모든 분석, 설계 작업 은 결국 최종 목적은 좋은 소스코드를 만들어 내는 것이다. $\mathrm{MDA}$ 툴은 컴파일처럼 플랫폼 독립적 모델로부터 플랫폼 종속적인 모델을 추출하고, 소스코드를 생성해서 최종적으 로 완전한 시스템을 구축한다.

기존의 케이스 툴도 모델로부터 소스코드를 생성하는 순 공학(Forward Engineering)을 지원하였으나, $\mathrm{MDA}$ 툴은 그 것을 뛰어 넘어 각 컴포넌트의 비즈니스 로직을 구현하고, 바로 실행시켜 서비스를 제공할 수 있는 하나의 완전한 시 스템을 구축한다는 것이 바로 $\mathrm{MDA}$ 의 기본 사상이다.

\subsection{MDA 기반 개발 프로세스의 기대효과 및 유효성 분석}

\subsubsection{MDA 기반 개발 프로세스의 기대효과}

$\mathrm{MDA}$ 를 적용하여 프로젝트를 개발함으로써 기대되는 효과 는 여러 가지가 있지만 대략 다섯 가지를 정의하여 보았다.

첫 번째, 생산성 향상이다. 이는 소스코드의 재사용과 소 스코드의 자동 생성을 통해 프로젝트로부터 중복적인 코딩 요소를 제거함으로써 효율성을 높일 수 있다.

두 번째, 비즈니스의 민첩성 향상이다. 이것은 필요한 수 준에 맞추어 애플리케이션 모델을 변화시킴으로써 변 화하는 비즈니스 요구에 대응하는 능력을 가지고 있다.

세 번째, 시스템 개발 및 유지보수 비용 절감과 개발기간 단축이다. 소프트웨어를 개발함에 있어 새로운 플랫폼으
로 자동 포팅해 줌으로써, 장기간에 걸친 생산 주기 동 안 소프트웨어의 유지보수 업무를 단순화 할 수 있다.

네 번째, 소프트웨어의 품질 향상이다. $\mathrm{MDA}$ 는 소스코드 개선의 필요성을 인식(코드 작성이 적을수록 예상되는 부담이 준다)하고 있으며, 소프트웨어 설계를 바탕으 로 한 테스트로 업계 표준 패턴이 자동으로 적용되어, 아키텍처와 설계 규정에 따른 일관성 유지 및 확장성 과 성능, 그리고 가용성을 확보하게 된다.

다섯 번째, 비즈니스 요구에 맞는 소프트웨어 생산이다. 이것은 변화하는 비즈니스 상황에 맞게 즉시 대처할 수 있는 소프트웨어 개발에 대한 신속한 접근방법으 로써, 변경되고 테스트된 애플리케이션의 청사진이 업계 표준으로서 소프트웨어를 제공하는데 많은 도움 과 기대가 된다.

\subsubsection{MDA 기반 개발 프로세스 유효성 분석}

$\mathrm{MDA}$ 를 지원하는 자동화 툴(Together Architecture 2006) 을 활용하여 학사관리 시스템을 플랫폼 독립적 모델(PIM)로 작성하고, 플랫폼 종속적 모델 $(\mathrm{PSM})$ 인 $\mathrm{J} 2 \mathrm{EE} / \mathrm{EJB}$ 미들웨 어로 매핑 룰을 적용하고 변환하여 구축된 학사관리 시스템 사례를 가지고, <표 $4.1>$ 와 같이 $\mathrm{MDA}$ 기반 개발 프로세스 에 대한 유효성 분석을 다음과 같이 유추해 볼 수 있다.

첫 번째, 소스코드의 자동 생성과 재사용, 프로젝트 내 중 복적인 요소 제거, 템플릿 및 변환 규칙을 적용한 설 계 자동화 및 시스템 분석, 관리, 검사 시간 절약 등에 대한 생산성 향상이 약 $40 \%$ 정도의 향상을 가질 수 있다.

두 번째, 소프트웨어의 유지보수 업무 단순화 및 문서화 작업 자동화, 개발 인력, 개발 기간 절감 효과 등에 대한 $\mathrm{CBD}$ 로 개발 시 약 $40 \%$, 타 방법으로의 개발 시 약 $30 \%$ 정도의 향상을 가질 수 있었다.

세 번째, 일관성 유지, 문서화 가능, 확장성의 용이, 가용 성 확보, 시스템 유지보수에 대한 리스크 관리, 시스 템 개발 시 반복적인 작업의 단순화, 창의성 극대화를 통한 소프트웨어에 대한 품질이 약 $30 \%$ 의 향상을 가 질 수 있다.

네 번째, 비즈니스 변화와 요구 대응 능력 및 변화하는 상황에 대한 즉시 대처능력과 소프트웨어 개발에 대 한 신속한 접근에 대해서는 대략 $15 \%$ 정도의 향상을 볼 수 있었다.

$\mathrm{MDA}$ 기반 개발 프로세스 유효성 분석에 대한 결과를 정 리해 보면 <표 4.1>와 같이 요약 할 수 있다.

(그림 4.5)와 같이 David Bertrand[7]는 개발 각 단계별 $\mathrm{MDA}$ 적용시와 $\mathrm{MDA}$ 비적용시의 비용 절감을 나타낸 것으로 분석 및 설계단계부터 각 단계별 비용절감을 나타내고 있다.

특히, 구현단계에서는 많은 비용 절감이 있는 것으로 나 타내고 있다. 
〈표 4.1〉MDA기반 개발 프로세스 유효성 분석

\begin{tabular}{|c|c|c|c|}
\hline \multicolumn{2}{|l|}{ 구 분 } & 효 율 & 비 고 \\
\hline \multicolumn{2}{|l|}{ 생산성 및 효율 성 향상 } & $40 \% \uparrow$ & $\begin{array}{l}\text { - 소스코드의 재사용 증가 } \\
\text { - 소스코드의 자동 생성 } \\
\text { - 프로젝트내 중복적인 요소 제거 } \\
\text { - 템플릭 및 변환 규칙을 적용한 설계자동화 } \\
\text { - 시스템 분석, 관리, 검사시간 절약 }\end{array}$ \\
\hline \multirow{2}{*}{$\begin{array}{l}\text { 시스템 개발 및 유지보수 } \\
\text { 비용 절감과 개발기간 단축 }\end{array}$} & CBD & $40 \% \uparrow$ & \multirow{2}{*}{$\begin{array}{l}\text { - 소프트웨어의 유지보수 업무를 단순화 } \\
\text { - 문서화 작업 자동화 } \\
\text { - 개발인력과 기간절감의 효과 등 }\end{array}$} \\
\hline & 객체, 일반 & $30 \% \uparrow$ & \\
\hline \multicolumn{2}{|l|}{ 소프트웨어 품질향상 } & $30 \% \uparrow$ & \begin{tabular}{|l} 
- 일관성 유지 \\
- 문서화 가능 \\
- 확장성 용이 \\
- 가용성 확보 \\
- 시스템 유지 보수의 리스크 관리 \\
- 개발의 반복적인 작업 단순화 \\
- 창의성 극대화
\end{tabular} \\
\hline \multicolumn{2}{|l|}{ 비즈니스의 민첩성 향상 } & $15 \% \uparrow$ & - 비즈니스 변화 요구 대응능력 \\
\hline \multicolumn{2}{|c|}{ 비즈니스 요구에 맞는 소프트웨어 생산 } & $15 \% \uparrow$ & $\begin{array}{l}\text { - 변화하는 비즈니스 상황에 맞게 즉시 대처 } \\
\text { - 소프트웨어 개발에 대한 신속한 접근방법 }\end{array}$ \\
\hline
\end{tabular}

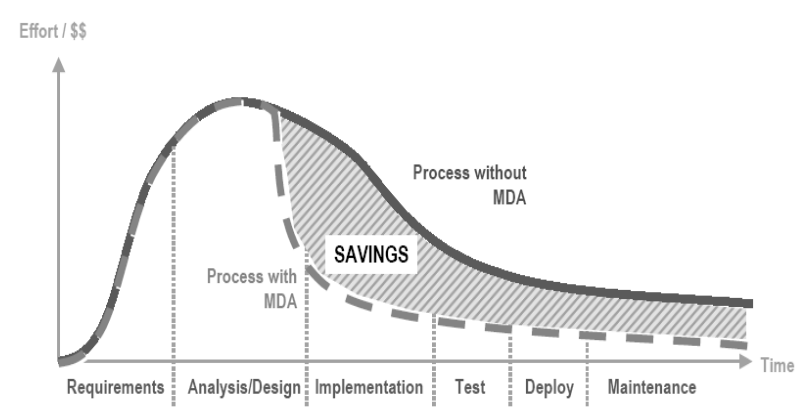

(그림 4.5) 각 단계별 $\mathrm{MDA}$ 적용시와 $\mathrm{MDA}$ 비적용시 비용 절감

\section{5. 결론 및 향후 연구과제}

본 논문에서는 $\mathrm{OMG}$ 에서 지금까지 추진한 여러 가지 표 준화 작업을 바탕으로 모델 중심의 시스템 명세와 개발 방 법인 $\mathrm{MDA}$ 에 대한 개괄적인 소개와 더불어 관련 표준 및 지원기술에 대해서 알아보고, $\mathrm{MDA}$ 방법론을 적용한 학사관 리 시스템에 대해 설계와 구현을 하였고, $\mathrm{MDA}$ 기반 개발 프로세스에 대한 유효성을 분석하였다.

$\mathrm{MDA}$ 방법론을 적용한 개발은 시스템의 구현 결과뿐만 아 니라, 분석 설계 관리 등의 프로젝트 진행 전체 결과를 재 사용 가능하게 한다. 특히 특정 기술에 종속 되어 있었던 개념적 설계와 물리적 설계를 분리함으로써, 기술 여건의 변화에 따라 동일한 개념적 설계를 반복하는 불필요한 작업 에 투입되는 노력을 줄여 줄 수 있었다. 그리고 설계 수준 의 시스템 통합을 기술함으로 지속적인 기술 여건 및 기반 기술의 발전에도 불구하고 적은 노력으로 시스템의 통합을 이루고, 상호 운용성을 유지할 수 있다.

또한 변환 규칙을 적용해서 모델의 자동 변환을 통해 다 중 플랫폼을 쉽게 지원하고, 개발자의 입장에서는 시간을 많이 필요로 하는 코드 작성 부분을 현격히 줄일 수 있으며, 개발 프로세서의 측면에서도 품질관리(Quality Assurance)
를 수월하게 할 수 있고, 기술 플랫폼과 기능 변화에 신속 한 대응, 시스템의 생명 주기 증가, 유지보수 용이, 개발 생 산성 증진, 용이한 문서 작성, 품질 관리 비용의 감소, 양질 의 시스템 구축, 개발 기간 단축, 다중 플랫폼에 대한 생산 성 향상 등의 효과를 기대할 수 있다.

$\mathrm{MDA}$ 기반 개발 프로세스가 전통적 개발 방법론에 비해 여러 가지 유효성 측면에서 효율성이 뛰어난 것을 확인할 수 있었다.

향후 $\mathrm{OMG}$ 의 지속적인 표준화 작업이 이루어 짐으로 인 해 현재 운용 되고 있는 전반적인 레거시 시스템에 대해서 도 표준화 작업이 되어야 할 것이며, 그리고 $\mathrm{MDA}$ 지원 툴 역시 순 공학과 역 공학에 대해 완전하게 지원이 이루어져 야 할 것이다. 또한 플랫폼 독립적 모델 설계 시 도메인에 대해 전반적이고 체계적인 지식을 갖고, $\mathrm{MDA}$ 방식을 적용 하여 성공적인 개발 사례가 늘어난다면, $\mathrm{UML}$ 로 SI업체 및 개발자 사회에서 보편적인 개발 패러다임으로 자리 잡아 갈 것으로 사료된다.

\section{참 고 문 헌}

[1] OMG, "Draft text for an MDA Guide.pdf," 2003.06.

[2] OMG Model Driven Architecture Home Page : www.omg. org./mda/index.htm.

[3] OMG, "UML 2.0 Specification," 2005.07.

[4] David Bertrand, "Model-Driven Architecture Case Study, "pp.5 6, June, 12, 2003.

[5] Jon Siegel and the OMG Staff Strategy Group, "Developing in OMG's Model Driven Architecture, “ftp://ftp.omg. org/docs/omg/00-11-05.pdf 2001.

[6] OMG, "Meta Object Facility”(MOF), 2006. 1.

[7] David Bertrand, "Model-Driven Architecture Case Study," pp.24, June 12, 2003.

[8] 권소정, " $\mathrm{MDA}$ 를 적용한 웹 기반 영화 예매 시스템 설계 및 구현," 2004. 12

[9] 이현주, "MDA기반 $\mathrm{EJB}$ 컴포넌트의 $\mathrm{PIM}$ 변환 규칙에 관한 연구," 2004. 7

[10] 천은영, "MDA구현을 위한 $\mathrm{EJB}$ 환경에서의 $\mathrm{UML}$ Profile 모델 설계 및 구현," 2004. 2.

[11] 김동규 이현정 정기원, ”PIM에서 $\mathrm{EJB}$ 기반의 $\mathrm{PSM}$ 으로 변 환에 대한 일관성 검증 규칙," 2004년도 한국정보과학회 가을 학술발표논문집 Vol.31, No.2, 2004.

[12] 박경민 “조직에서의 $\mathrm{MDA}$ 추진 전략과 전술," 마이크로소 프트, 2004. 8. 


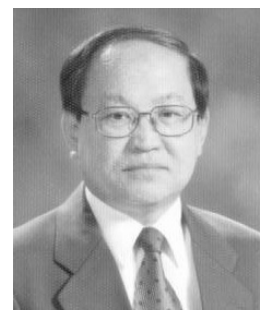

\section{윤 정 모}

e-mail : jmyoon@snut..ac.kr

1968년 광운대학교 응용전자공학과 (공학사)

1971년 성균관대학교 경영행정대학원 (경영학석사)

1993년 일본오사카부립대학교 대학원 경영공학과(공학박사)

1966년 1982년 한국전력공사 전자계산소 과장대리 1983년 1988년 서울산업대학교 전자계산소장 겸임 2002년 2003년 일본오사카부립대학 객원교수 1982년 현재 서울산업대학교 컴퓨터공학과 교수

관심분야: 객체지향 분석설계, 소프트웨어 공학, UML, ERP 등

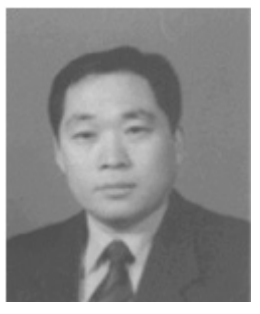

김 치 호

e-mail : chk1363@naver.com

2001년 서울산업대학교 전자계산학과 (학사)

2006년 서울산업대학교 산업대학원 컴퓨터공학과 (공학석사)

1979년 1981년 삼익악기제조(주) 전산실 근무

1981년 1984년 동국무역(주) 전산실 근무

1984년 2001년 주식회사 E1[구 LG Caltex Gas(주)] 정보기술팀 근무

2001년 현재 서울특별시립 상계직업전문학교 웹프로그래밍과 교사, 서울산업대학교 공과대학 컴퓨터공학과 출강

관심분야: 시스템개발방법론, 데이터베이스, 정보보안, 시스템 감리 등 